\title{
ARTÍCULO 17
}

"Transferencia de fondos

Los Estados Parte en los que estén vigentes regímenes de capitalización individual podrán establecer mecanismos de transferencia de fondos a los fines de la percepción de prestaciones por invalidez, vejez o muerte”.

\section{PEDRO CONTADOR ABRAHAM}

Magister. Profesor de Derecho del Trabajo y Seguridad Social

Escuela de Derecho, Universidad de Talca-Chile

\section{PATRICIA MONJES MC HUGH}

Abogada. Magister en Gerencia y Políticas Públicas

Universidad Adolfo Ibáñez-Chile

e-Revista Internacional de la Protección Social, ISNN 2445-3269.2016, Vol. I, № 2 


\title{
RESUMEN
}

Los Convenios de Seguridad Social han asumido tradicionalmente la función de otorgar protección al trabajador migrante, a través de ciertos principios rectores, entre los cuales se encuentran el reconocimiento y totalización de períodos de seguro o de cotizaciones y el pago a prorrata de beneficios, aplicándose en lo demás la legislación interna de los países involucrados. Con el establecimiento en algunos países de sistemas de pensiones basados en la capitalización individual, se han ido modificando estos criterios. Primero replicando en los Convenios de Seguridad Social la regla en virtud de la cual, los afiliados a estos sistemas deben financiar sus prestaciones con el saldo acumulado en sus cuentas de capitalización individual, hasta permitir como hace el artículo 17 del Convenio Multilateral Iberoamericano de Seguridad Social, que los Estados Parte celebren acuerdos de traspaso o transferencia de fondos entre sistemas de capitalización individual, a objeto de financiar las prestaciones que les correspondan en virtud del Convenio. Sin embargo, es posible constatar que la citada norma no menciona ni hace referencia a algunos de los elementos esenciales para el desarrollo de estos acuerdos, dejando estas definiciones a las negociaciones de los Estados que resuelvan celebrarlos. Mientras ello no ocurra, parece ser ilustrativo conocer el alcance, contenidos y resultados del acuerdo de transferencia de fondos previsionales, materializado bajo el amparo del Convenio de Seguridad Social entre Chile y Perú.

PALABRAS CLAVE: Convenio Multilateral Iberoamericano de Seguridad Social, Convenio de Seguridad Social entre Chile y Perú, acuerdos de transferencia o traspaso de fondos previsionales, sistemas de capitalización individual.

\begin{abstract}
Traditionally, Social Security Agreements have assumed the protection of migrant workers through certain guiding principles among which is the recognition and aggregation of periods of insurance or contributions and pro rata payment of benefits, while internal legislation of the countries involved applies in everything else. With the establishment in some countries of pension systems based on individual capitalization, these criteria have been changing, first replicating in the Social Security Agreements the rule under which affiliates of these systems must finance their benefits with the accumulated balance in their individual capitalization accounts to allow States Parties, as does Article 17 of the Iberoamerican Multilateral Agreement on Social Security, to enter into agreements on portability or transfer of funds between individual capitalization systems, in order to finance the benefits that apply under said Agreement. However, it is verified that the abovementioned rule does not refer to some essential elements for the development of these agreements, leaving these definitions to the negotiations of the States that decide to enter into them. As long as this is the case, it seems instructive to know the scope, content and outcome of the agreement on transfer of pension funds, materialized pursuant to the Agreement on Social Security between Chile and Peru.
\end{abstract}

e-Revista Internacional de la Protección Social, ISNN 2445-3269.2016, Vol. I, No 2

http://dx.doi.org/10.12795/e-RIPS.2016.102.18

Página 194 
KEYWORDS: Iberoamerican Multilateral Agreement on Social Security, Agreement on Social Security between Chile and Peru, agreements on portability or transfer of pension funds, individual capitalization systems.

e-Revista Internacional de la Protección Social, ISNN 2445-3269.2016, Vol. I, No 2 
SUMARIO

I. LA FINALIDAD, FUNDAMENTOS Y MECANISMOS DE APLICACIÓN DE UN CONVENIO DE SEGURIDAD SOCIAL

II. EL TRASPASO O TRANSFERENCIA DE FONDOS EN EL CONVENIO MULTILATERAL IBEROAMERICANO DE SEGURIDAD SOCIAL

III. NATURALEZA JURÍDICA DE LOS MECANISMOS QUE PERMITEN EL TRASPASO O TRANSFERENCIA DE FONDOS

IV. EL TRASPASO O TRANSFERENCIA DE FONDOS EN EL CONVENIO DE SEGURIDAD SOCIAL ENTRE CHILE Y PERÚ

V. REQUISITOS PARA EL TRASPASO O TRANSFERENCIA DE FONDOS EN EL CONVENIO CHILENO-PERUANO DE SEGURIDAD SOCIAL

VI. NATURALEZA Y EFECTOS DEL TRASPASO O TRANSFERENCIA DE FONDOS EN EL CONVENIO CHILENO-PERUANO DE SEGURIDAD SOCIAL

VII. NÚMERO Y MONTO TOTAL EN DÓLARES, DE TRASPASOS O TRANSFERENCIAS DE FONDOS EFECTUADOS ENTRE SISTEMAS DE CAPITALIZACIÓN INDIVIDUAL DE CHILE Y PERÚ

VIII. ALGUNAS CONSIDERACIONES A TENER EN CUENTA PARA CELEBRAR UN ACUERDO DE TRASPASO O TRANSFERENCIA DE FONDOS PREVISIONALES

IX. CONCLUSIONES

e-Revista Internacional de la Protección Social, ISNN 2445-3269.2016, Vol. I, N 2 


\section{LA FINALIDAD, FUNDAMENTOS Y MECANISMOS DE APLICACIÓN DE UN CONVENIO DE SEGURIDAD SOCIAL ${ }^{1}$}

Los Convenios de Seguridad Social pueden ser definidos como instrumentos jurídicos de carácter internacional, suscritos por dos o más Estados, que tienen por finalidad atender las necesidades de seguridad social -en particular el derecho a recibir pensiones- que enfrentan los trabajadores y trabajadoras migrantes y sus familias, que prestan o han prestado servicios en uno o más Estados Parte del Convenio.

$\mathrm{Su}$ fundamento se encontraría en la necesidad de establecer normas supraestatales de continuidad previsional, que resguarden el derecho de los trabajadores migrantes a mantener los beneficios de seguridad social, que se encontraban en posibilidad de adquirir al salir de un determinado país, para ingresar al sistema de previsión social de otra nación.

Con este objeto el acceso al derecho a la pensión se regula conforme a la normativa interna de cada uno de los Estados Parte, estableciendo los Convenios ciertas reglas de concurrencia de cada Parte para la constitución de la pensión. En los sistemas de seguridad social basados en el reparto, esta contribución se efectúa a través de uno de los principios de los Convenios de Seguridad Social, cual es la "totalización de períodos de seguro, cotizaciones o empleo", en virtud de la cual los períodos cotizados o considerados como tales, en uno de los Estados Parte, son reconocidos en otro de los Estados, para efectos de adquirir, mantener o recuperar derechos previsionales. La totalización de períodos de seguros admite, en el evento que resulte necesario y siempre que no se superpongan, sumar los períodos acreditables en ambos o varios Estados, cuestión que le permitirá al afiliado "abrir" idealmente el derecho a prestaciones de seguridad social en uno, ambos o varios de los Estados Parte. No obstante ello, las reglas de cálculo y pago de estas prestaciones se rigen por la ley interna que resulte aplicable y solo por los períodos de seguros, cotizaciones o empleo efectivamente efectuados en el país de que se trata.

Sin embargo, esta forma de computar cotizaciones previsionales registradas en un tercer país, no puede aplicarse a los sistemas de capitalización individual, en los que el derecho a la pensión no se adquiere por la acreditación de un número mínimo de años de cotizaciones, sino que por el cumplimiento de la edad para pensionarse por vejez, pues la regla general es que las pensiones en este tipo de sistemas, se financien exclusivamente con el saldo acumulado en la cuenta de capitalización individual del respectivo afiliado. No obstante lo anterior y aunque la información de datos de afiliación o de cotizaciones en otros países, pudiera no resultar relevante para el financiamiento de las prestaciones, esos tiempos de cotización o afiliación pueden ser informados al otro Estado Parte, para efectos de cumplir eventualmente los años exigidos por dicho Estado para acceder a una pensión. Por tal razón, los Convenios de Seguridad Social suscritos por los Estados Parte que cuentan con

\footnotetext{
${ }^{1}$ Extractado de Cifuentes Lillo, H.; Arellano Ortiz, P.; y Walker, Errázuriz, F.; Seguridad Social, Parte General y Pensiones. Librotecnia. Santiago de Chile. 2013, pp. 167-174. Y Contador Abraham, P. El Tratamiento de las Prestaciones no Contributivas en el Marco de los Convenios de Seguridad Social ratificados por Chile. En Arellano Ortiz, P. (Ed.). Trabajadores Migrantes y Seguridad Social. Librotecnia. Santiago de Chile. 2015, pp. 101-108.
}

e-Revista Internacional de la Protección Social, ISNN 2445-3269.2016, Vol. I, No 2 http://dx.doi.org/10.12795/e-RIPS.2016.102.18

Página 197 
sistemas de capitalización individual, suelen reconocer el derecho de sus afiliados a totalizar períodos de seguro, cotizaciones o empleo para impetrar el beneficio de garantía estatal de pensión mínima, no contemplándose hasta ahora y salvo lo que se indicará a continuación, mecanismos de traspaso de fondos en tales instrumentos internacionales ${ }^{2}$.

Cabe indicar finalmente que las reglas antes descritas, aplicables a los sistemas de capitalización individual están expresamente previstas en el apartado 1 del artículo $16^{3}$ y en el artículo 17 del Convenio Multilateral Iberoamericano de Seguridad Social.

\section{EL TRASPASOO TRANSFERENCIA DE FONDOS EN EL CONVENIO MULTILATERAL IBEROAMERICANO DE SEGURIDAD SOCIAL}

El Convenio Multilateral Iberoamericano de Seguridad Social, en su Capítulo 2 del Título II denominado "Coordinación entre regímenes y legislaciones basada en el ahorro y la capitalización" prescribe en su artículo 17 que "Los Estados Parte en los que estén vigentes regímenes de capitalización individual podrán establecer mecanismos de transferencia de fondos a los fines de la percepción de prestaciones por invalidez, vejez o muerte”.

Del análisis de esta norma internacional, es posible concluir que para que opere la transferencia de fondos entre los Estados Parte del Convenio Multilateral Iberoamericano de Seguridad Social, deben concurrir los siguientes requisitos:

1. Ser Estado Parte del Convenio Multilateral Iberoamericano de Seguridad Social, vale decir, que el Estado sea miembro de la Comunidad Iberoamericana ${ }^{4}$ y que haya firmado, ratificado, aceptado o adherido a este Convenio, conforme lo disponen los artículos 29 y 30 de ese instrumento 5 .

${ }^{2}$ Cifuentes Lillo, H.; Convenio Multilateral y Seguridad Social Chilena, Capítulo XI en: González Ortega, S. (Coordinador); El Convenio Multilateral Iberoamericano de Seguridad Social. Tirant Lo Blanch. 2013, pp. 365-366.

3“ARTÍCULO 16.- Régimen de prestaciones

1. Cuando se trate de regímenes de capitalización individual, los afiliados a la Entidad Administradora de Fondos de Pensiones o institución similar financiarán sus pensiones con el saldo acumulado en su cuenta de capitalización individual, en los términos establecidos en la legislación del Estado Parte de que se trate.

Si, de acuerdo a la legislación de un Estado Parte en el que se liquide la pensión se garantiza una pensión mínima, cuando la pensión generada con el saldo acumulado en la cuenta de capitalización individual fuera insuficiente para financiar pensiones de una cuantía al menos igual al de la citada pensión mínima, la institución competente del Estado Parte en el que se liquide la pensión procederá a la totalización de los períodos cumplidos en otros Estados Parte, de acuerdo al artículo 5, para acceder al beneficio de pensión mínima de vejez o invalidez en la proporción que corresponda, calculada de conformidad a lo dispuesto por el artículo 13. Igual derecho tendrán los beneficiarios de pensión de supervivencia.".

${ }^{4}$ La Comunidad Iberoamericana, está integrada por los siguientes países: Andorra, Argentina, Bolivia, Brasil, Colombia, Costa Rica, Cuba, Chile, República Dominicana, Ecuador, El Salvador, España, Guatemala, Honduras, México, Nicaragua, Panamá, Paraguay, Perú, Portugal, Uruguay y Venezuela. Visto en: http://segib.org/paises/ (22.08.2016).

5 “ARTÍCULO 29. - Firma

El presente Convenio estará abierto a la firma de los Estados Miembros de la Comunidad Iberoamericana.”.

e-Revista Internacional de la Protección Social, ISNN 2445-3269.2016, Vol. I, No 2

http://dx.doi.org/10.12795/e-RIPS.2016.i02.18

Página 198 
2. Que el Convenio Multilateral Iberoamericano de Seguridad Social haya entrado en vigencia $^{6}$, respecto de los Estados Parte que celebren estos mecanismos de transferencia de fondos.

3. Que estos Estados Parte mantengan un sistema de capitalización individual dentro de sus esquemas de seguridad social.

Al efecto, cabe indicar que tradicionalmente la doctrina ha hecho presente que cuando se menciona a los sistemas de capitalización, normalmente se está refiriendo a una forma de organización de los regímenes financieros de la seguridad social, es decir, a la regulación de sus ingresos, reservas y a su plan de inversiones, lo que en definitiva constituye el método por el cual se van a asignar los recursos de la seguridad social, para la satisfacción de los estados de necesidad que sufren sus afiliados y sus familias, siendo los regímenes de capitalización, aquellos que se formulan en base a la capitalización o a la inversión de los fondos que se aportan para su financiamiento, los que juntos con la rentabilidad que generan, permiten financiar las respectivas prestaciones. Dicha acumulación de recursos se prolonga por períodos extensos que se determinan actualmente, con el objeto de obtener además los intereses que financiarán, tanto las prestaciones como los gastos de administración. La capitalización individual, por su parte, se caracteriza porque el sistema abre una cuenta individual con las cotizaciones obligatorias de los propios afiliados y los aportes del empleador y el Estado, si existieren?

En el caso del sistema de capitalización individual chileno, los fondos previsionales son de propiedad del afiliado, ya sea que se registren en su cuenta de capitalización individual de cotizaciones obligatorias y voluntarias, de depósitos convenidos, así como de ahorro previsional individual o colectivo, o bien en alguna de las otras cuentas voluntarias que

“ARTÍCULO 30.- Ratificación, aceptación, aprobación o adhesión

1. El presente Convenio estará sujeto a ratificación, aceptación o aprobación. Los instrumentos de ratificación, aceptación o aprobación se depositarán en la Secretaría General Iberoamericana a través de la OISS.

2. El presente Convenio estará abierto a la adhesión de todos los Estados que forman parte de la Comunidad Iberoamericana. Los instrumentos de adhesión se depositarán en la Secretaría General Iberoamericana a través de la OISS.”.

"ARTÍCULO 31.- Entrada en vigor

1. El Convenio entrará en vigor el primer día del tercer mes siguiente a la fecha en que se haya depositado el séptimo instrumento de ratificación, aceptación, aprobación o adhesión. No obstante, éste producirá efectos entre dichos Estados una vez que el Acuerdo de Aplicación sea suscrito por los mismos.

2. Para cada Estado que ratifique o se adhiera al presente Convenio después de haberse depositado el séptimo instrumento de ratificación, aceptación, aprobación o adhesión, entrará en vigor el primer día del tercer mes siguiente a la fecha en que ese Estado haya depositado el instrumento pertinente, no obstante éste producirá efectos una vez que el Acuerdo de Aplicación sea suscrito por el mismo. La Secretaría General Iberoamericana a través de la OISS comunicará dicho acto a los demás Estados Parte.”.

${ }^{7}$ Lanata Fuenzalida, G.; Manual de Legislación Previsional. Editorial Legal Publishing. Santiago de Chile. 2014, pp. 37- 43.

e-Revista Internacional de la Protección Social, ISNN 2445-3269.2016, Vol. I, № 2

http://dx.doi.org/10.12795/e-RIPS.2016.i02.18

Página 199 
contempla el sistema, conforme lo disponen los artículos 20, $20 \mathrm{~A}, 20 \mathrm{~F}, 20 \mathrm{H}^{8}$ y 21 del decreto ley $\mathrm{N}^{\circ} 3.500$, de 1980, del Ministerio del Trabajo y Previsión Social.

Asimismo se ha indicado, que en este tipo de sistema de pensiones cada afiliado posee una cuenta individual, donde se depositan sus cotizaciones previsionales las cuales se capitalizan y ganan la rentabilidad de las inversiones, que las administradoras realizan con los recursos de los fondos que gestionan. Al término de la vida activa, este capital le es devuelto al afiliado o a sus beneficiarios sobrevivientes en la forma de alguna modalidad de pensión. La cuantía de las pensiones dependerá del monto del ahorro, existiendo por lo tanto una relación directa entre el esfuerzo personal y la pensión que se obtenga ${ }^{9}$.

Respeto del objeto de estos acuerdos entre los Estados Parte, ellos deben permitir, por un lado, la transferencia de fondos entres sus sistemas de capitalización individual y segundo, deben tener por exclusiva finalidad la percepción de prestaciones por vejez, invalidez o muerte, en los términos del apartado 1 del artículo 3 del Convenio ${ }^{10}$. De esta forma y dado que la característica fundamental de los sistemas de capitalización individual, es que por regla general los afiliados financian sus prestaciones con el saldo acumulado en su cuenta de capitalización individual ${ }^{11}$, no sería posible que los acuerdos celebrados bajo el amparo del citado artículo 17, tuvieran por objeto directo o indirecto, permitir la devolución o retiro de los fondos acumulados en las referidas cuentas de capitalización individual.

Asimismo, y si bien el artículo 17 del Convenio Multilateral Iberoamericano de Seguridad Social no prevé el registro de este tipo de acuerdo, creemos que es pertinente, por analogía,

\footnotetext{
${ }^{8}$ Artículo $20 \mathrm{H}$ del decreto ley $\mathrm{N}^{\circ} 3.500$, de 1980, establece que “Los recursos originados en los aportes efectuados por el trabajador serán siempre de su propiedad. Por su parte, los recursos originados en los aportes efectuados por el empleador serán de propiedad del trabajador una vez que se cumplan las condiciones establecidas en el contrato respectivo. De esta forma, si el contrato de ahorro establece un período mínimo de permanencia en la empresa, para que los aportes del empleador sean definitivamente de propiedad del trabajador, se requerirá que éste cumpla integramente dicho período o que se configure algunas de las causales establecidas expresamente en el contrato para ello.”.

${ }^{9}$ A partir de definición dada para el sistema de capitalización individual chileno, por la Superintendencia de Pensiones. Visto en: http://www.safp.cl/safpstats/stats/sist_previsional/cont2_sistema.html (22.08.2016).

10 "Artículo 3.- Campo de aplicación material

1. El presente Convenio se aplicará a toda la legislación relativa a las ramas de seguridad social relacionadas con:

a) las prestaciones económicas de invalidez;

b) las prestaciones económicas de vejez;

c) las prestaciones económicas de supervivencia; $y$,

d) las prestaciones económicas de accidentes de trabajo y de enfermedad profesional.".

${ }^{11}$ Como se indicara anteriormente, el mecanismo de financiamiento de las prestaciones a través del acumulado en la cuenta de capitalización individual, está expresamente previsto en el apartado 1 del artículo 16 del Convenio Multilateral Iberoamericano de Seguridad Social. En el caso chileno, así se establece en el artículo 51 del decreto ley $\mathrm{N}^{\circ}$ 3.500, de 1980 que establece el Sistema de Pensiones de Vejez, de Invalidez y Sobrevivencia derivado de la capitalización individual.
}

e-Revista Internacional de la Protección Social, ISNN 2445-3269.2016, Vol. I, No 2 http://dx.doi.org/10.12795/e-RIPS.2016.i02.18

Página 200 
que estos acuerdos se registren en el anexo III del Convenio, contenido en el apartado 5 de su artículo $3^{12}$.

Ahora bien, conforme a la información disponible ${ }^{13}$, los países de la Comunidad Iberoamericana que tienen un sistema de capitalización individual o alguno de sus elementos que lo caracterizan son los siguientes: Bolivia, Chile, Colombia, Costa Rica, El Salvador, México, Perú, Panamá, República Dominicana y Uruguay. De estos países, de acuerdo a la información proporcionada por la Organización Iberoamericana de Seguridad Social $^{14}$, solo Bolivia, Chile, El Salvador, Perú y Uruguay, estarían en condiciones hoy de celebrar acuerdo de transferencia de fondos a que se refiere el artículo 17 del Convenio, por tener la calidad de Estados Parte del Convenio, en tanto que Colombia, Costa Rica y República Dominicana únicamente han suscrito el Convenio Multilateral Iberoamericano de Seguridad Social.

\section{NATURALEZA JURÍDICA DE LOS MECANISMOS QUE PERMITENEL TRASPASO O TRANSFERENCIA DE FONDOS}

Considerando que el citado artículo 17 del Convenio Multilateral Iberoamericano de Seguridad Social, sólo establece requisitos marco para la celebración de los acuerdos de transferencia de fondos, pero sin definir su contenido ni sus finalidades específicas, así como tampoco se contienen regulaciones o directrices generales en materias o puntos que son cruciales para un acuerdo de esta naturaleza, entendemos que para dar eficacia a la transferencia de fondos entre los Estados Parte del Convenio, se requeriría un nuevo tratado internacional ${ }^{15}$ entre los países involucrados, conforme la definición que otorga el artículo 2 letra a) ${ }^{16}$ de la Convención de Viena de 1969 sobre el Derecho de los Tratados. En este sentido, debe recordarse que de acuerdo el artículo 11 de la misma Convención, el consentimiento de un Estado en obligarse por un tratado, puede manifestarse mediante la

\footnotetext{
${ }^{12}$ Artículo 3, apartado $\mathrm{N}^{\circ}$ 5: "Dos o más Estados Parte del presente Convenio podrán ampliar el ámbito objetivo del mismo, extendiéndolo a prestaciones o regímenes excluidos en principio. Los acuerdos bilaterales o multilaterales mediante los que se proceda a esa extensión y los efectos de la misma se inscribirán en el Anexo III. Las reglas correspondientes a los regímenes y/o prestaciones que hayan sido objeto de extensión, conforme a lo previsto en el apartado anterior, afectarán únicamente a los Estados que las hayan suscrito, sin que surtan efectos para los demás Estados Parte.”.

${ }^{13}$ Información proporcionada por la Federación Internacional de Administradoras de Fondos de Pensiones (FIAP). Visto en: http://www.fiapinternacional.org/en/pension-systems-reform/ (22.08.2016).

${ }^{14}$ Visto en: http://www.oiss.org/Estado-de-Situacion.html(14.11.2016).

${ }^{15}$ Doctrinariamente se ha definido al tratado internacional como un acuerdo de voluntades celebrado por escrito entre sujetos de derecho internacional y regido por el derecho internacional. En Vargas Carreño, Edmundo. Derecho Internacional Público, de acuerdo a las normas y prácticas que rigen en el Siglo XXI. Editorial Jurídica de Chile, Santiago de Chile. 2007, p. 124.

16 "a) Se entiende por "tratado" un acuerdo internacional celebrado por escrito entre Estados y regido por el derecho internacional, ya conste en un instrumento único o en dos o más instrumentos conexos y cualquiera que sea su denominación particular.”.
}

e-Revista Internacional de la Protección Social, ISNN 2445-3269.2016, Vol. I, No 2

http://dx.doi.org/10.12795/e-RIPS.2016.i02.18

Página 201 
firma, el canje de instrumentos que constituyan un tratado, la ratificación, la aceptación, la aprobación o la adhesión, o en cualquier otra forma que se hubiere convenido y que a su vez, la letra b) del citado artículo 2 de la Convención, entiende por "ratificación", “aceptación”, "aprobación” y "adhesión”, según el caso, el acto internacional por el cual un Estado hace constar en el ámbito internacional su consentimiento en obligarse por un tratado.

Sobre la ratificación se ha señalado que es el respectivo derecho constitucional, el que determina cuáles el órgano interno llamado a efectuar la ratificación, generalmente tal función corresponde a los Jefes de Estado, quien ordinariamente requiere la aprobación previa del Parlamento para proceder a la ratificación de ciertos tratados. Como contrapartida, la práctica internacional contemporánea ha tendido a abreviar los trámites de conclusión de un tratado. Así, el procedimiento de ratificación, precedido de una aprobación parlamentaria, no es ya exigido por las Constituciones más modernas, sino solo para determinado tipo de $\operatorname{tratados}^{17}$.

El Acuerdo de Aplicación, indicado en el artículo 21 del Convenio Multilateral Iberoamericano de Seguridad Social, así como los acuerdos entre las Autoridades Competentes a que se refieren los artículos 3, 8, y 11 del Convenio, están sujetos a este procedimiento simplificado de conclusión y entrada en vigencia, más aún si el propio Convenio que autoriza a celebrarlos, ya fue sujeto de ratificación por los Estados Parte.

Sin embargo y como se señalara, el artículo 17 del Convenio además de permitirla celebración de los acuerdos para establecer los mecanismos de transferencia de fondos y definir su finalidad esencial, no describe el contenido de esta transferencia, las cotizaciones que comprende, el destino de los fondos traspasados, los requisitos para que opere la transferencia, el régimen tributario o impositivo que será aplicable entre los países involucrados en el acuerdo, si el traspaso de fondos implicará la desafección o desvinculación de la seguridad social del país que transfirió los fondos, etc. En definitiva, puede estimarse que el artículo 17 del Convenio carece de suficiente densidad de normas sustantivas, cuestión que dificulta enormemente a los Estados Parte, acogerse a un acuerdo simplificado que le dé ejecución o desarrollo a un mecanismo de transferencia de fondos.

En efecto, y a lo menos en el modelo constitucional chileno conforme al artículo 54 numeral 1) inciso cuarto de su Constitución Política, las medidas que el Presidente de la República adopte o los acuerdos que celebre para el cumplimiento de un tratado en vigor, no requerirán de nueva aprobación del Congreso - como podrían ser considerados en un primer análisis aquellos que se refiere el artículo 17 del Convenio-, a menos que se trate de materias propias de ley, carácter que tiene la garantía constitucional del derecho a la seguridad social, por lo que necesariamente tales acuerdos deben someterse a la aprobación previa del Congreso Nacional ${ }^{18}$.

\footnotetext{
${ }^{17}$ En Vargas Carreño, E.; Derecho Internacional Público, de acuerdo a las normas y prácticas que rigen en el Siglo XXI. Editorial Jurídica de Chile. Santiago de Chile. 2007, pp. 128-133.

18 “Artículo 19.- La Constitución asegura a todas las personas. 18..- El derecho a la seguridad social.
}

e-Revista Internacional de la Protección Social, ISNN 2445-3269.2016, Vol. I, No 2 http://dx.doi.org/10.12795/e-RIPS.2016.102.18

Página 202 
En consecuencia, podemos concluir que la norma del artículo 17 del Convenio Multilateral Iberoamericano de Seguridad Social es esencialmente programática, ya que si bien permite el establecimiento de mecanismos de transferencia de fondos entre sistemas de capitalización individual, en definitiva tales mecanismos no fueron sustancialmente regulados, como si se hizo para la determinación de las prestaciones de invalidez, vejez y supervivencia, a través del mecanismo de totalización de períodos de seguro, de cotización o de empleo, propios de los regímenes de reparto, en el Capítulo 1 del Título II del Convenio.

La dificultad antes apuntada se puede constatar revisando el estado de situación actual del Convenio, pues a la fecha a pesar de encontrarse actualmente vigente y operativo en once Estados Parte ${ }^{19}$, aún no se conocen que se hayan suscrito acuerdos que permitan la portabilidad de fondos entre sistemas de capitalización individual, situación que nos lleva a la necesidad de efectuar una breve revisión de la regulación, así como de los resultados del mecanismo sobre la portabilidad o transferencia de fondos contenido en el Convenio de Seguridad Social entre la República de Chile y la República del Perú, que es el único instrumento internacional en materia de seguridad social, que contempla este tipo de beneficio para los afiliados a regímenes de capitalización individual, de los cuales se pudieran extraer elementos de juicio para analizar la factibilidad de extender el mecanismo de transferencia de fondos, como forma de conceder beneficios de seguridad social al amparo de un Convenio Internacional.

\section{EL TRASPASO O TRANSFERENCIA DE FONDOS EN EL CONVENIO DE SEGURIDAD SOCIAL ENTRE CHILE Y PERÚ}

El Convenio de Seguridad Social entre Chile y Perú fue suscrito el 23 de agosto de 2002 en la ciudad de Santiago de Chile y entró en vigencia internacional, el $1^{\circ}$ de abril de 2004, de conformidad a lo establecido en su artículo 29. Su Acuerdo Administrativo para la Implementación del Convenio, también fue suscrito en la ciudad de Santiago, el 23 de agosto de 2005 y entró en vigor el $1^{\circ}$ de octubre de 2006. Finalmente, este marco normativo es concluido por el Acuerdo Complementario para la Transferencia de Fondos Previsionales entre la República de Chile y la República del Perú, suscrito en la ciudad de Lima, Perú con fecha 26 de mayo de 2006, entre la ex Superintendencia de Administradoras de Fondos de Pensiones de Chile, hoy la Superintendencia de Pensiones ${ }^{20}$ y la Superintendencia de Banca, Seguros y Administradoras de Fondos de Pensiones del Perú.

Las leyes que regulen el ejercicio de este derecho serán de quórum calificado.”.

"Artículo 63.- Sólo son materias de ley:

4) Las materias básicas relativas al régimen jurídico laboral, sindical, previsional y de seguridad social;”.

${ }^{19}$ Visto en: www.http://www.oiss.org/Estado-de-Situacion.html(14.11.2016).

${ }^{20}$ De conformidad al artículo 46 de la ley $\mathrm{N}^{\circ} 20.255$, la Superintendencia de Pensiones de Chile, es la continuadora legal de la Superintendencia de Administradoras de Fondos de Pensiones, creada por el decreto ley $\mathrm{N}^{\circ} 3.500$, de 1980 .

e-Revista Internacional de la Protección Social, ISNN 2445-3269.2016, Vol. I, No 2

http://dx.doi.org/10.12795/e-RIPS.2016.i02.18

Página 203 
Cabe señalar que el artículo 18 del Convenio de Seguridad Social entre Chile y Perú, reconoce el derecho de los afiliados a los sistemas de capitalización individual a la transferencia de sus fondos previsionales, con el fin de que éstos sean administrados por una Administradora de Fondos de Pensiones o AFP del país en que residirán definitivamente, estableciendo normas que contienen los requisitos para que opere dicho beneficio, como también expresando que la finalidad que se pretende obtener a través de la transferencia de fondos, es el otorgamiento de prestaciones en los sistemas de pensiones involucrados.

Al respecto, cabe señalar que el apartado 2 del artículo 18 del Convenio de Seguridad Social entre Chile y Perú contiene las disposiciones que permiten la transferencia de fondos entre el Sistema de Pensiones creado por el decreto ley $\mathrm{N}^{\circ} 3.500$, de 1980, del Ministerio del Trabajo y Previsión Social y el Sistema Privado de Pensiones del Perú (SPP) ${ }^{21}$.

\section{REQUISITOS PARA EL TRASPASO O TRANSFERENCIA DE FONDOS EN EL CONVENIO CHILENO-PERUANO DE SEGURIDAD SOCIAL}

1. Según el artículo 18 del Convenio de Seguridad Social entre Chile y Perú, se exigen ciertos requisitos copulativos para la procedencia de la transferencia de fondos entre el Sistema de Pensiones del decreto ley $\mathrm{N}^{\circ} 3.500$, de 1980 y el Sistema Privado de Pensiones del Perú, a saber:

Solo procede respecto de los afiliados a algún sistema de capitalización individual.

Se debe acreditar residencia permanente y un período de 60 meses cotizados en el sistema previsional basado en capitalización individual, en el país al que se desea traspasar los fondos. Cabe señalar que el apartado 2 del artículo 18 del Convenio prevé que este requisito de aportación en el país de destino, podrá ser modificado por acuerdo de las Autoridades Competentes de ambas Partes, ya sea ampliándolo o bien reduciéndolo.

No será necesario acreditar un período mínimo de aportaciones, en caso de tener la calidad de beneficiario de pensión en el país de destino.

Se debe traspasar la totalidad de los fondos.

Saldo a traspasar. El trabajador que opta por trasladar sus recursos previsionales, se le deberá incluir la totalidad de los mismos, es decir, las cotizaciones obligatorias; bono de reconocimiento; cotizaciones voluntarias y depósitos convenidos. En el caso que no correspondiera la liquidación del bono de reconocimiento, éste será transado en el mercado secundario formal del país donde se retiran los fondos. De no disponer esta transacción, se comunicará que el monto se enviará cuando se liquide el respectivo instrumento.

\footnotetext{
${ }^{21}$ Texto Único Ordenado Ley del Sistema Privado de Administración de Fondos de Pensiones del Perú, Decreto Ley $N^{\circ} 25897$ y modificatorias. Decreto Supremo Nº54-97-Ministerio de Economía y Finanzas, publicado el 14 de mayo de 1997.
}

e-Revista Internacional de la Protección Social, ISNN 2445-3269.2016, Vol. I, No 2 
Tributación. Como existe una asimetría en los regímenes legales tributarios o impositivos de ambos países, lo que se expresa que en Chile se tributa por las pensiones ${ }^{22}$ y en Perú por los aportes, el Convenio dispone que los beneficios previsionales que se otorguen en Chile, quedarán afectos a las normas de tributación chilena, solo en la parte cuyo financiamiento corresponda a los aportes efectuados en Chile y a la rentabilidad de los fondos traspasados. Respecto a los fondos que se traspasen desde Chile a Perú, el Convenio establece que solo el retiro de los aportes voluntarios estará afecto a las normas tributarias chilenas.

Garantía Estatal de Pensión Mínima ${ }^{23}$. El Convenio establece que solo es aplicable la legislación del país de destino, por cuanto la portabilidad genera una desvinculación con el sistema previsional del país de origen.

Procedimiento. Cabe hacer presente que tanto en el artículo $8^{\circ}$ del Acuerdo Administrativo como en el Acuerdo Complementario, se establecen normas y un detallado procedimiento que regulan la transferencia de fondos entre las Administradoras de Fondos de Pensiones de ambos Estados y que pueden resumirse en lo siguiente:

Presentación por el propio interesado o bien por un mandatario especialmente facultado para estos efectos, de la solicitud de transferencia de fondos en la AFP del país de destino,

\footnotetext{
${ }^{22}$ En el caso chileno, la jubilación o pensión es un ingreso para el jubilado o pensionado, al que se aplica la tributación general de la Ley sobre Impuesto a la Renta (LIR), y por tanto es constitutivo de renta, al no estar incluida en la lista taxativa de Ingresos No constitutivos de Renta del artículo 17 de la LIR.

En consecuencia, se afectan con Impuesto de Segunda Categoría (impuesto a las rentas del trabajo) las pensiones o jubilaciones mensuales superiores a 13,5 Unidades Tributarias Mensuales (UTM) (US\$955 mensuales aproximadamente) y con Impuesto Global Complementario (impuesto personal sobre el total de las rentas) las rentas anuales inferiores a 13,5 Unidades Tributarias Anuales (UTA) (US\$11.459 anuales aproximadamente).

Por ello, por regla general, dependiendo de su monto, la jubilación o pensión está afecta al Impuesto Único a los Trabajadores, que es retenido y enterado al Fisco mensualmente por la institución pagadora de la respectiva jubilación o pensión. En aspectos generales de la tributación de pensiones y jubilaciones. Minuta de la Biblioteca del Congreso Nacional.

Visto:

en:www.bcn.cl/obtienearchivo?id=repositorio/10221/15614/1/JPCH_\%20MInuta_Tributacion\%20de\%20pen siones\%20y\%20jubilaciones_.doc. (22.08.2016).

${ }^{23}$ La garantía estatal de pensión mínima consistía en un beneficio que pagaba el Estado chileno a los pensionados de vejez, invalidez o sobrevivencia del decreto ley $\mathrm{N}^{\circ} 3.500$, de 1980 que operaba, en términos generales, una vez que se agotaban los fondos depositados en sus cuentas de capitalización individual, en la modalidad de pensión de retiro programado o bien, cuando la modalidad de renta vitalicia convenida llegaba a ser inferior a al monto de la pensión mínima.

Las disposiciones sobre el beneficio de garantía estatal de pensión mínima (artículos 73 a 81 de decreto ley $\mathrm{N}^{\circ} 3.500$, de 1980), hoy se encuentran derogadas por el artículo quinto transitorio de la ley $\mathrm{N}^{\circ} 20.255$ y otorgaban esta prestación para los afiliados de 65 años o más si son hombres y 60 años de edad o más si son mujeres y requería, para tener derecho a ella, de 20 y 10 años de cotizaciones en cualquier sistema previsional para la vejez y sobrevivencia, respectivamente. Tratándose de la invalidez se exigía como mínimo 2 años de cotizaciones previsionales en los últimos 5 años anteriores a la invalidez, o estar cotizando al momento en que sea declarada la invalidez en caso que ocurra un accidente o completar 10 años de imposiciones efectivas. Para beneficiarse de la garantía estatal era necesario que la persona que lo solicitaba no percibiera pensiones, rentas y remuneraciones imponibles iguales o superiores a la respectiva pensión mínima (antiguo artículo 80 del decreto ley $\left.\mathrm{N}^{\circ} 3.500\right)$.
}

e-Revista Internacional de la Protección Social, ISNN 2445-3269.2016, Vol. I, No 2

http://dx.doi.org/10.12795/e-RIPS.2016.102.18

Página 205 
la cual debe ser presentada en la AFP del país de residencia, con la cédula de identidad para extranjeros y el certificado de residencia definitiva.

Verificación de la solicitud y documentación anexa por la AFP receptora, dentro de los 10 días hábiles desde la recepción (Se debe verificar que el solicitante cuente con el requisito de 60 meses de cotizaciones al sistema de capitalización individual del país de destino, o bien que tenga la calidad de beneficiario de pensión).

Dentro de los 15 días hábiles siguientes a la recepción de la solicitud, la AFP receptora deberá rechazar la solicitud, si el afiliado no cumple los requisitos exigidos, informando de ello al afiliado dentro de los 5 días hábiles siguientes.

Certificado de afiliación dentro de los 15 días hábiles. Se remite a la AFP del país de origen, además del original de la solicitud de transferencia y el certificado de residencia en el país de destino.

Aceptada la solicitud de transferencia, la AFP de origen deberá constituir el saldo total de la cuenta individual, incluyendo las cotizaciones voluntarias y los depósitos convenidos y proceder a efectuar las gestiones de recuperación de tales cotizaciones si fuere necesario, en caso de cotizaciones en rezago o con morosidad, así como la emisión y liquidación del bono de reconocimiento, si corresponde.

La transferencia de fondos debe ser efectuada en un plazo máximo 90 días calendarios siguientes, a la fecha de recepción de la solicitud de transferencia por parte de la AFP de origen.

La AFP de origen deberá mantener abierta la cuenta de capitalización individual, hasta la recuperación total de los fondos involucrados.

La desvinculación del sistema de seguridad social en el país de origen, se produce cuando se haya transferido la totalidad del saldo del afiliado, no quedando rubros pendientes.

La recepción de fondos en el país de destino, deberán ser ingresados por la AFP de destino en la cuenta individual del trabajador en calidad de cotizaciones obligatorias.

Finalmente, se establece que la AFP del país de origen conjuntamente con emitir la constancia de la transferencia de los fondos previsionales del trabajador, debe enviar a la AFP de destino los antecedentes en que se funda la solicitud. 


\section{NATURALEZA Y EFECTOS DEL TRASPASO O TRANSFERENCIA DE FONDOS EN EL CONVENIO CHILENO-PERUANO DE SEGURIDAD SOCIAL}

Sobre este punto, es importante mencionar que a partir de la lectura de los apartados 1 y 2 del indicado artículo $18^{24}$ del Convenio de Seguridad Social entre Chile y Perú, es posible sostener que la finalidad de la transferencia de fondos entre los sistemas de capitalización individual, es permitir la consolidación de la situación previsional del trabajador, en el país en el cual residirá en forma definitiva, de manera tal que pueda incrementar sus fondos, a objeto poder acceder a mejores beneficios en el sistema de capitalización individual conforme al cual se pensione ${ }^{25}$.

En cuanto a los efectos que esta transferencia de fondos produce en el sistema de seguridad social del país de origen, cabe recordar que el artículo 18 del Convenio establece que al optar el trabajador por trasladar sus recursos previsionales, debe incorporar la totalidad de éstos, es decir, las cotizaciones obligatorias, el bono de reconocimiento, las cotizaciones voluntarias y los depósitos convenidos. De modo tal que el artículo $9^{\circ}$ del Acuerdo Complementario del Convenio dispone que una vez efectuada la transferencia total de los fondos previsionales del trabajador hacia la Administradora de Fondos de Pensiones del país de destino, se producirá su desvinculación total del sistema previsional del país de origen, de tal manera que él no podrá invocar derecho a prestación alguna en aquel país.

En este contexto, puede plantearse la discusión si los efectos de la desvinculación a la seguridad social del país de origen alcanzan o no, tanto a las prestaciones contributivas como a las no contributivas que éste otorga y, si esta exclusión comprende o no a la certificación de períodos de seguro o cotización, efectuadas inicialmente en el país de origen antes del traspaso de fondos, con el propósito de acceder a la garantía estatal de

\footnotetext{
24 “Artículo $18^{\circ}$

Traspaso de Fondos Previsionales entre Sistemas de Capitalización

1. Para efecto de las prestaciones que otorgue el Sistema de Capitalización Individual de Chile y el Sistema Privado de Pensiones de Perú, se reconoce el derecho de los trabajadores de transferir el saldo acumulado en sus cuentas de capitalización individuales de una Parte Contratante a otra, con el fin que sean administrados por la Administradora Privada de Fondos de Pensiones de su elección.

2. El traslado de fondos implica la transferencia de los fondos de pensiones depositados en sus cuentas individuales de capitalización hacia otra Entidad Gestora o Institución Competente del sistema de capitalización individual del otro país, en donde se vaya a residir de modo permanente. Para garantizar la naturaleza previsional, se deberá acreditar aportación a un sistema de capitalización individual de al menos 60 meses o tener la calidad de pensionado en el país al que se desea trasladar los fondos. Las Autoridades Competentes, de común acuerdo, podrán establecer la ampliación o reducción del mencionado límite. Para tal efecto, este proceso implica el traslado de los recursos de la cuenta individual más el bono de reconocimiento, si lo hubiera, y en tanto se cumpla con los requisitos de redención o liquidación de cada país, de acuerdo a lo estipulado en el numeral 4.".
}

${ }^{25}$ Sin embargo, a partir de la dictación en el Perú de la ley $\mathrm{N}^{\circ} 30.425$ de 21 de abril 2016, que estableció diversas causales y porcentajes para la devolución de fondos a los afiliados del Sistema Privado de Pensiones, se abre la interrogante de si esta finalidad única de la transferencia de fondos entre sistemas de capitalización individual se mantendrá en el tiempo.

e-Revista Internacional de la Protección Social, ISNN 2445-3269.2016, Vol. I, No 2

http://dx.doi.org/10.12795/e-RIPS.2016.i02.18

Página 207 
pensión mínima en el país de destino, percibiendo de esa manera una proporción del beneficio en función de los años cotizados bajo esa legislación.

\section{NÚMERO Y MONTO TOTAL EN DÓLARES, DE TRASPASOS O TRANSFERENCIAS DE FONDOS EFECTUADOS ENTRE SISTEMAS DE CAPITALIZACIÓN INDIVIDUAL DE CHILE Y PERÚ}

De acuerdo a la información oficial ${ }^{26}$, la transferencia de fondos desde Chile a Perú en el período enero-diciembre de 2015, fue de US\$2.541.175 y durante el mismo período, la transferencia de fondos desde Perú a Chile alcanzó la cifra de US\$ 3.529.116.

Por su parte, en el período 2007-2015 se han aprobado 946 solicitudes de transferencia de fondos, de las cuales 460 correspondieron a traspasos de Chile a Perú y 486 en sentido inverso. El siguiente cuadro muestra, desde que entró en vigencia este sistema, una tendencia al aumento tanto del número como de los montos comprometidos de las solicitudes de transferencia de fondos, cuestión que permite aseverar que este mecanismo constituye una opción no solo conocida, sino que utilizada por los flujos migratorios de ambos países, que cumplen los requisitos establecidos para la transferencia de fondos previsionales entre Chile y Perú ${ }^{27}$.

Número y montos de transferencias de fondos efectuados convenio de seguridad social Chile-Perú

\section{CUADRO 1}

\begin{tabular}{|c|c|r|c|r|}
\hline Años & $\begin{array}{c}\text { Transferencias } \\
\text { desde Chile a Perú }\end{array}$ & Monto US\$ & $\begin{array}{c}\text { Transferencias desde } \\
\text { Perú a Chile }\end{array}$ & Monto US\$ \\
\hline 2007 & 3 & 39.560 & 22 & 1.434 .749 \\
\hline 2008 & 16 & 78.631 & 38 & 1.673 .824 \\
\hline 2009 & 30 & 310.401 & 34 & 1.141 .798 \\
\hline 2010 & 43 & 728.842 & 50 & 1.898 .309 \\
\hline 2011 & 44 & 1.519 .892 & 62 & 2.864 .936 \\
\hline 2012 & 62 & 1.610 .132 & 55 & 1.958 .044 \\
\hline 2013 & 69 & 696.679 & 81 & 3.787 .499 \\
\hline 2014 & 85 & 1.122 .387 & 56 & 1.798 .876 \\
\hline 2015 & 108 & 2.541 .175 & 88 & 3.529 .116 \\
\hline Total & 460 & 8.647 .699 & 486 & 20.087 .151 \\
\hline
\end{tabular}

\footnotetext{
${ }^{26}$ Visto en: http://www.spensiones.cl/safpstats/stats/pageCCEE.php?menu=sci\&item=trfclpe (22.08.2016).

${ }^{27}$ Visto en: https://www.previsionsocial.gob.cl/sps/biblioteca/convenios-internacionales-de-seguridad-social/ (22.08.2016).
}

e-Revista Internacional de la Protección Social, ISNN 2445-3269.2016, Vol. I, No 2 


\section{ALGUNAS CONSIDERACIONES A TENER EN CUENTA PARA CELEBRAR UN ACUERDO DE TRASPASO O TRANSFERENCIA DE FONDOS PREVISIONALES ${ }^{28}$}

A partir de los planteamientos antes formulados, y producto de la experiencia acumulada en la aplicación del Convenio de Seguridad Social entre Chile y Perú, en particular de aquella derivada del acuerdo de transferencia de fondos, es posible delinear un conjunto de criterios que se deben considerar y definir previamente antes de negociar un tratado de esta naturaleza:

-Oportunidad del traspaso de fondos: se debe evaluar el establecimiento de restricciones a la oportunidad del traspaso de fondos, con el objeto de evitar traslados por motivos meramente especulativos y no previsionales, particularmente en períodos de diferencias sustanciales de rentabilidad entre los países involucrados. Asimismo, se deberían adoptar medidas para evitar que grandes traspasos de fondos coyunturales, afecten tanto a los mercados de capitales como cambiarios de los respectivos Estados Parte. Por tanto se deberá resolver, si el traspaso se producirá durante la vida activa del trabajador o al momento de acogerse a pensión en el país de destino.

-Legislación aplicable: traspasados los fondos, solo se debiera aplicar la legislación del país de destino. De esta forma el traspaso debería estar limitado al traslado de cuentas y no involucrar el traslado o reconocimiento de otros derechos, generándose de esta forma una desvinculación del sistema previsional del país de origen. En este punto debería resolverse si el trabajador perderá su derecho a beneficios no contributivos, bajo la legislación del país desde el cual retira sus fondos previsionales, pues de lo contrario, se sometería a los Estados a otorgar estas prestaciones en base a legislaciones y riesgos económicos de otros países.

-Período mínimo de cotizaciones: correspondería exigir que el afiliado haya realizado aportes en los Estados Parte, siendo necesario estudiar la posibilidad de establecer un período mínimo de cotizaciones en los Estados, de manera que el monto a traspasar justifique los costos de la operación.

-Modalidad del traspaso de fondos: se debe estudiar la simplicidad del sistema, así como evaluar los costos operativos que conlleva, tomando en cuenta además si dicho traspaso involucrará la totalidad de los recursos previsionales en una misma oportunidad o no.

-Voluntariedad de la portabilidad: el traspaso debe ser voluntario, debido a que puede conllevar una desvinculación del sistema previsional en el país de origen, que puede significar una pérdida importante de beneficios del pilar contributivo de la seguridad social.

-Reconocimiento de cotizaciones del sistema de reparto: se deberá evaluar si los aportes a dicho sistema, se considerarán de alguna forma en los montos traspasados.

${ }^{28}$ Análisis extraído de Oficio $\mathrm{N}^{\circ} 13990$, de 12 octubre de 2010, de la Superintendencia de Pensiones de Chile. e-Revista Internacional de la Protección Social, ISNN 2445-3269.2016, Vol. I, No 2 http://dx.doi.org/10.12795/e-RIPS.2016.i02.18

Página 209 
-Regímenes tributarios o impositivos: Al no existir uniformidad en la legislación de los Estados Parte, el traspaso de fondos provocará ciertas situaciones que deben tenerse presentes al momento de negociar este tipo de beneficios. Entre ellas:

-Cuando las cotizaciones obligatorias estén exentas y las pensiones se encuentren afectas al impuesto a la renta.

-Cuando las cotizaciones obligatorias estén afectas a impuestos a la renta y las pensiones encuentren exentas.

-Cuando, tanto las cotizaciones obligatorias como las pensiones estén exentas.

En cualquiera de estos escenarios, se podrían incentivar los traspasos de fondos por razones especulativas aprovechando las ventajas tributarias, especialmente en el retiro de excedentes de libre disposición ${ }^{29}$ o las cotizaciones voluntarias comprendidos en el saldo a traspasar.

\section{CONCLUSIONES}

Si bien el artículo 17 del Convenio Multilateral Iberoamericano de Seguridad Social, permite a los Estados Parte celebrar acuerdos que establezcan mecanismos para el traspaso de fondos entre sistemas de capitalización individual, a los fines de percibir las prestaciones de invalidez, vejez o muertes amparadas por el Convenio, su escaso desarrollo normativo ha dejado enteramente a las negociaciones entre las Partes, la definición de aspectos medulares para el funcionamiento de estos acuerdos de traspaso. Esta misma consideración, permite afirmar que se requeriría que los Estados Parte celebren un nuevo tratado internacional y dicten la normativa complementaria, a fin de resolver los aspectos mínimos que hagan operativo el sistema.

1. No se conocen hasta la fecha iniciativas entre países, encaminadas a concretar un acuerdo de transferencia de fondos en el marco del Convenio Multilateral Iberoamericano de Seguridad Social.

2. El acuerdo de traspaso de fondos contenido en el Convenio de Seguridad Social entre Chile y Perú, constituye la primera experiencia que de forma concreta plantea un mecanismo de concurrencia al financiamiento de las prestaciones de los trabajadores migrantes, distinta a la totalización de períodos de seguro, de cotizaciones o de empleo y al pago a prorrata de las prestaciones, reconociéndoles el derecho de los trabajadores de transferir el saldo acumulado en sus cuentas de capitalización individuales de uno de los Estados Parte al otro, con el fin que sean

\footnotetext{
${ }^{29}$ En el caso chileno, los excedentes de libre disposición son fondos remanentes en la cuenta de capitalización individual, luego de efectuado el cálculo del monto necesario para la obtención de pensión y descontado del saldo acumulado, el cual queda a disposición del afiliado para los usos que estime conveniente, siempre que tenga a lo menos diez años de afiliación en cualquier sistema previsional; obtenga una pensión igual o mayor al $70 \%$ del promedio de las remuneraciones percibidas y rentas declaradas de los últimos diez años anteriores al mes en que se acogió a pensión, y que la pensión obtenida sea igual o superior al 100\% de la pensión máxima con aporte solidario, vigente a la fecha que se acoja a pensión. Visto en: http://www.safp.cl/portal/orientacion/580/w3-propertyvalue-6159.html (22.08.2016).
}

e-Revista Internacional de la Protección Social, ISNN 2445-3269.2016, Vol. I, No 2 
administrados por la AFP de su elección y para efectos de acceder a las prestaciones que otorgue el sistema de capitalización individual de Chile o Perú, pretendiendo de esta forma asegurar la naturaleza estrictamente previsional y no especulativa del mecanismo.

3. En este mismo contexto, se inscriben la exigencias en orden a que el traspaso comprenda la totalidad de las cotizaciones obligatorias y voluntarias, incluidos sus rendimientos acumulados en la cuenta individual del afiliado en el país de origen, y que para proceder al traspaso deban registrarse un mínimo de 60 meses de cotizaciones u otro que se determine, así como contar con residencia permanente en el país donde se vayan a transferir los fondos.

4. Asimismo, no deben de perderse de vista los efectos que un mecanismo de traspaso de fondos pudieran generar en la seguridad social del país de origen, particularmente en lo que se refiere a la desvinculación que produciría.

5. Finalmente, la diversidad de la legislación tributaria de los países involucrados, es también un elemento a considerar a la hora definir el mecanismo de traspaso de fondos. 